\title{
SCAI/AATS/ACC/STS operator and institutional requirements for transcatheter valve repair and replacement, part III: Pulmonic valve
}

\author{
Ziyad M. Hijazi, MD, MPH, ${ }^{\mathrm{a}}$ Carlos E. Ruiz, MD, PhD, ${ }^{\mathrm{b}}$ Evan Zahn, MD, ${ }^{\mathrm{c}}$ Richard Ringel, MD, ${ }^{\mathrm{d}}$ \\ Gabriel S. Aldea, MD, ${ }^{\mathrm{e}}$ Emile A. Bacha, MD, ${ }^{\mathrm{f}}$ Joseph Bavaria, MD, ${ }^{\mathrm{g}}$ R. Morton Bolman III, MD, \\ Duke E. Cameron, MD, ${ }^{\mathrm{i}}$ Larry S. Dean, MD ${ }^{\mathrm{j}}$ Ted Feldman, MD, ${ }^{\mathrm{k}}$ David Fullerton, MD, ${ }^{\mathrm{l}}$ Eric Horlick, MDCM, ${ }^{\mathrm{m}}$ \\ Michael J. Mack, MD ${ }^{\mathrm{n}}$ D. Craig Miller, MD, ${ }^{\circ}$ Marc R. Moon, MD, ${ }^{\mathrm{p}}$ Debabrata Mukherjee, MD, ${ }^{\mathrm{q}}$ \\ Alfredo Trento, MD, ${ }^{\mathrm{r}}$ and Carl L. Tommaso, MD
}

See related commentary on page 1261 .

\section{PREAMBLE}

With the evolution of transcatheter valve replacement, an important opportunity has arisen for cardiologists and surgeons to collaborate in identifying the criteria for performing these procedures. Therefore, The Society for Cardiovascular Angiography and Interventions (SCAI), American Association for Thoracic Surgery (AATS), American College of Cardiology (ACC), and The Society of Thoracic Surgeons (STS) have partnered to provide recommendations for institutions to assess their potential for instituting and/or maintaining a transcatheter valve program. This article concerns transcatheter pulmonic valve replacement (tPVR). tPVR procedures are in their infancy with few reports available on which to base an expert consensus statement. Therefore, many of these recommendations are based on expert consensus and the few reports available. As the procedures evolve, technology advances, experience grows, and more data accumulate, there will certainly be a need to update this consensus statement. The writing committee and participating societies believe that the recommendations in this report serve as appropriate requisites. In some ways, these recommendations apply to institutions more than to individuals. There is a strong consensus

\footnotetext{
Sidra Cardiovascular Center of Excellence, ${ }^{a}$ Department of Pediatrics, Sidra Medical \& Research Center, Doha, Qatar; Lenox Hill Heart \& Vascular Institute of New York, ${ }^{\mathrm{b}}$ New York, NY; Guerin Family Congenital Heart Program, ${ }^{\mathrm{c}}$ Cedars-Sinai Heart Institute, Cedars-Sinai Medical Center, Los Angeles, California; Pediatric Cardiac Catheterization Laboratory, ${ }^{\mathrm{d}}$ The Johns Hopkins Hospital, Baltimore, Md; Regional Heart Center, ${ }^{\text {e }}$ University of Washington Medical Center, Seattle, Wash; Pediatric Cardiac Surgery, ${ }^{\mathrm{f}}$ New York-Presbyterian/Columbia University Medical Center, Morgan Stanley Children's Hospital, New York, NY; Division of Cardiothoracic Surgery, ${ }^{\mathrm{g}}$ Hospital of the University of Pennsylvania, Philadelphia, Pa; Division of Cardiac Surgery, ${ }^{\text {h }}$ Harvard Medical School, Boston, Mass; The Dana and Albert "Cubby" Broccoli Center for Aortic Diseases, ${ }^{\text {i }}$ The Johns Hopkins Hospital, Baltimore, Md; University of Washington ${ }^{\mathrm{j}}$ School of Medicine, Seattle, Washington; Cardiac Catheterization Laboratory, ${ }^{\mathrm{k}}$ Evanston Hospital, Evanston, Ill; Cardiothoracic Surgery, ${ }^{1}$ University of Colorado Denver, Aurora, Colo; Peter Munk Cardiac Centre, ${ }^{\mathrm{m}}$ Toronto General Hospital, Toronto, Ontario, Canada; Cardiovascular Council Dallas, ${ }^{n}$ Heart Hospital Baylor, Plano, Tex; Department of Cardiovascular Surgery, ${ }^{\circ}$ Stanford University School of Medicine, Stanford, Calif; Division of Cardiothoracic Surgery, ${ }^{\mathrm{p}}$ Washington University, St. Louis, Mo; Department of Internal Medicine ${ }^{\mathrm{q}}$ Cardiovascular Medicine, Texas Tech University, El Paso, Tex; Division of Cardiothoracic Surgery, ${ }^{\mathrm{r}}$ Cedars-Sinai
}

that these new valve therapies are best performed using a Heart Team approach; thus, these credentialing criteria should be applied at the institutional level. Partnering societies used the ACC's policy on relationships with industry (RWI) and other entities to author this document (http://www.acc.org/guidelines/about-guidelines-and-clinicaldocuments). To avoid actual, potential, or perceived conflicts of interest due to industry relationships or personal interests, all members of the writing committee, as well as peer reviewers of the document, were asked to disclose all current healthcare-related relationships including those existing 12 months before the initiation of the writing effort. A committee of interventional cardiologists and surgeons was formed to include a majority of members with no relevant RWI and to be led by an interventional cardiology cochair and a surgical cochair with no relevant RWI. Authors with relevant RWI were not permitted to draft or vote on text or recommendations pertaining to their RWI. RWI were reviewed on all conference calls and updated as changes occurred. Author and peer reviewer RWI pertinent to this document are disclosed in the Appendices. In addition, to ensure complete transparency, authors' comprehensive disclosure information (including RWI not pertinent to this document) is available in Appendix Table 2. The work of the writing committee was supported exclusively by the partnering societies without commercial support. SCAI, AATS, ACC, and STS believe that adherence to these

Medical Center, Los Angeles, Calif; and Cardiac Catheterization Laboratory, Skokie Hospital, North Shore University Health System, Skokie, Ill.

This article is copublished in The Journal of Thoracic and Cardiovascular Surgery, Catheterization and Cardiovascular Interventions, The Annals of Thoracic Surgery, and Journal of the American College of Cardiology.

Copies: This document is available on the World Wide Web sites of The American Association for Thoracic Surgery (http://www.aats.org), The Society of Thoracic Surgeons (http://sts.org), the American College of Cardiology (http://www.cardiosource.org), and the Society for Cardiovascular Angiography and Interventions (http://www.scai.org). Received for publication Oct 8, 2014; accepted for publication Oct 10, 2014; available ahead of print March 24, 2015.

Address for reprints: Ziyad M. Hijazi, Sidra Cardiovascular Center of Excellence, Department of Pediatrics, Sidra Medical \& Research Center, Doha, Qatar (E-mail: zhijazi@sidra.org).

J Thorac Cardiovasc Surg 2015;149:e71-8 $0022-5223 / \$ 36.00$

Copyright (C) 2015 by The American Association for Thoracic Surgery, The Society for Cardiovascular Angiography and Interventions, and The Society of Thoracic Surgeons

http://dx.doi.org/10.1016/j.jtcvs.2015.02.058 
recommendations will maximize the chances that these therapies will become a successful part of the armamentarium for treating valvular heart disease in the United States. In addition, these recommendations will hopefully facilitate optimum quality during the delivery of this therapy, which will be important to the development and successful implementation of future, less invasive approaches to structural heart disease.

\section{INTRODUCTION}

Enabled by the development of new technologies, treatment of valvular heart disease by transcatheter techniques has complemented standard surgical approaches, thus providing enhanced care for our patients. Transcatheter techniques offer a less invasive treatment for patients who were previously treatable only with open-heart surgery or, in many cases, who were not treatable at all. Recognition from the medical community of the applicability, effectiveness, and practicality of transcatheter valve therapies has further increased interest in these treatments. Training program content, standards, credentialing, and board certifications for cardiac surgical procedures and percutaneous coronary intervention are well developed, but no such structure exists in the field of percutaneous structural or valvular heart disease therapies. The purpose of this article is to outline criteria for operator and institutional requirements, to help enable institutions and providers to participate responsibly in this new and rapidly developing field.

The emergence of transcatheter pulmonic valve implantation as an alternative to traditional surgical therapy for valvular diseases has been facilitated by innovative devices, rapidly developing techniques, and careful patient selection. The combination of interventional skills, equipment, collaborative clinical management, surgical approaches, techniques, and decision making distinguishes the qualifications to participate in this field as unique, as does the complexity of the patients who require these therapies. Given both the high-risk nature of these catheter interventions and the availability of established alternative treatment options using traditional surgical approaches, several considerations are important for institutions and operators planning to implement these new technologies.

Defining operator and institutional requirements for these novel therapies is an important first step to ensure their optimal implementation. Part 1 of this series concerning transcatheter aortic valve replacement (TAVR) was previously published. The authors felt that the facilities and institutional requirements have remained unchanged; thus, those sections have not been repeated here and may be found in the previous report. ${ }^{1}$

\section{PULMONIC VALVE REPLACEMENT}

Some congenital cardiac defects require surgical reconstruction of the right ventricular outflow tract (RVOT). This procedure may entail pulmonic valve replacement or placement of a pulmonic valve/conduit between the right ventricle (RV) and pulmonary artery. Over time, these reconstructions often develop valve dysfunction, leading to pulmonary regurgitation and/or stenosis. Pulmonary stenosis and/or regurgitation may lead to right ventricular dysfunction associated with exercise intolerance, dysrhythmias, heart failure, and an increased risk of sudden cardiac death. ${ }^{2}$ Biological valves are typically implanted in the pulmonary position, commonly in children and young adults. Given the limits of the durability of biological valves, these patients are likely to undergo serial open-heart surgical procedures over the course of their lifetimes.

Treatment of RVOT stenosis in patients following tetralogy of fallot (TOF) repair or for those with a conduit between the RV and the pulmonary artery with balloon dilatation has been used with limited and often short-lived success. RVOT conduit stenting has been shown to decrease RV pressure and to extend conduit lifespan. ${ }^{3,4}$ However, this treatment option usually produces free pulmonary regurgitation, which may be severe as the leaflets of the previously placed valve/conduit are rendered incompetent by the stent. Severe pulmonary regurgitation has significant long-term deleterious effects including progressive RV dilation and dysfunction, dysrhythmias, and sudden cardiac death. ${ }^{2}$ ACC/AHA 2014 focused guidelines for management of patients with valvular heart disease and ACC/AHA 2014 guidelines for the management of adults with congenital heart disease ${ }^{5,6}$ provided the indications for pulmonary valve replacement for pulmonary regurgitation in postoperative patients with TOF: symptoms associated with severe pulmonary insufficiency or in the absence of symptoms, magnetic resonance imaging (MRI) criteria for severe pulmonary insufficiency including: RVEDV of $>150$ $\mathrm{mL} / \mathrm{m}^{2}$; pulmonary regurgitant fraction $>40 \%$ and $\mathrm{RV}$ ejection fraction $<40 \%$.

The operative risk is acceptably low $(0.9 \%-1.2 \%)$ for the first operation to implant a RV-pulmonary artery conduit. ${ }^{7,8}$ A recent report from Ong et $\mathrm{al}^{7}$ demonstrated that freedom from reoperation increased with successive interventions from $50 \%$ at 10 years following implantation of the first conduit to $74 \%$ and $86 \%$ at 10 years for the second and third conduit replacement, respectively. Pulmonary homograft replacement during the Ross procedure was associated with even greater durability with a reintervention incidence of 1 in 150 patient-years, ${ }^{9}$ and reoperative rates seem to be lower with larger conduits. ${ }^{10}$ Patients may require multiple operations over a lifetime, as the mean time to reoperation is about 10.3 years for xenografts and 16 years for homografts. ${ }^{11,12}$ Tweddell et $\mathrm{al}^{11}$ reported that at about 1-2 years after homograft replacement, $16 \%$ of patients had conduit dysfunction and at about 4-5 years, almost $50 \%$ of the homografts were dysfunctional. In that article, $25 \%$ of the patients had reoperations at about $4-5$ 
years after conduit replacement. These reoperations are often complex and involve increasing morbidity (blood transfusions, mediastinitis, etc) and mortality over time. ${ }^{13}$ Currently, there is no established or validated operative risk calculator or score for pulmonary valve replacement. Thus, assessment of operative risk is highly limited to clinical judgment of the operator, which may be inaccurate due to bias.

The potential need for repeat surgery in this patient population makes transcatheter pulmonic valve replacement (tPVR) to replace an obstructed and/or regurgitant pulmonary bioprosthesis or conduit an attractive option. In 2000, Bonhoeffer et al. ${ }^{14,15}$ reported the first experimental and clinical human application of a transcatheter valve in the pulmonary position in a 12-year-old patient with a previously implanted conduit for pulmonary atresia. In 2005, in a compassionate use case, a transcatheter pulmonary valve (Edwards SAPIEN valve; Edwards Lifesciences, Irvine, Calif) was placed in a 16-year-old boy with congenital severe aortic stenosis who had undergone a Ross operation. ${ }^{16}$

Since then, more than 6000 patients have received percutaneously placed pulmonary valves (Ms. Jill Hennesen, Medtronic Inc, personal communication). Few reports from outside the United States have been published. ${ }^{17,18}$ In 2010, the Melody valve (Medtronic Corporation, Minneapolis, Minn) was approved by the United States Food and Drug Administration (FDA) under Humanitarian Device Exemption. ${ }^{19,20}$ In January 2015, the Melody valve received full premarket approval (PMA). The SAPIEN valve is currently being used outside the United States ${ }^{21}$ and is under clinical investigation in the United States for use in the RVOT (COMPASSION trial; Edwards Lifesciences). ${ }^{22}$ Currently, there are no data published in the literature to indicate the total number of percutaneous pulmonary valves implanted in the United States. Furthermore, no data are published on the average number of procedures performed by various operators/institutions. Such data will be important to collect going forward. With current valve technology, pretreatment of the RVOT with bare metal stent implantation appears to offer several advantages including: creation of a landing zone for valve placement, elimination of conduit stenoses prior to the valve implant and a decrease in the incidence of stent/valve fracture that may lead to early valve failure. $^{20,22}$ For detailed technical aspects of the procedure, the readers are referred to a chapter written by one of the authors of this document. ${ }^{23}$ The procedure in general is safe; however, there are potential complications that can be encountered during or after the procedure. The rate of serious complications in the US Melody trial $^{19,20}$ was reported at $6 \%$, including death from coronary dissection $(n=1)$, conduit rupture $(n=1)$, unstable arrhythmia $(n=1)$, wire perforation in distal pulmonary artery $(n=2)$, and femoral vein thrombosis $(n=1)$. In the COMPASSION trial, ${ }^{22}$ the rate of serious complications was $21 \%$ (7 patients). Valve or stent migration occurred in 4 patients (3 requiring surgical retrieval and 1 was deployed in the inferior vena cava), unstable arrhythmias in 1 patient, and self-limited wire perforation in the distal pulmonary arteries in 2 patients. These complications can be divided into the following: procedural: pulmonary hemorrhage (secondary to guide wire); ventricular arrhythmias; stent embolization (prestenting); coronary artery compression; ${ }^{24}$ conduit rupture and valve embolization. Complications at follow-up: stent fracture and infective endocarditis. ${ }^{25}$ While these complications were initially reported to be as high as $12 \%$ in early smaller tPVR studies, ${ }^{17}$ more recent trials have shown a decrease of these adverse events to $5 \% 6 \%{ }^{20}$ This decrease in procedural complications is most likely due to increased operator experience. In 2008, Bonhoeffer's group published a study looking at the learning curve for tPVR since it was first used in 2001. They reported that after their initial 50 patients, the incidence of procedural complications fell to $2.9 \%{ }^{18}$

Institutions/operators that desire to embark on transcatheter pulmonary valve implantation should meet certain requirements:

\section{Institutional Requirements}

Table 1 summarizes the institutional and operator requirements to embark on tPVR. These include but are not limited to the following:

1. Cardiac cases requirements

The institution should perform 150 congenital/structural catheterization procedures per year. Of those, 100 should be interventional in nature, including but not limited to stenting of branch pulmonary arteries and RVOT. The rationale for this number is the large number of various procedures performed in a congenital laboratory and the need for large number of inventory products. Furthermore, the institution should perform a minimum of a 100 open-heart surgical procedures in patients with congenital heart disease (if a Children's hospital) or an adult program associated with a Children's hospital. The adult program should perform a minimum of 25 adult-congenital surgical cases per year.

\section{Staffing requirements}

The institution should have a Heart Team (interventional cardiologists [pediatric trained or adult trained, as long as they have the expertise in this area], cardiac surgeons, noninvasive cardiologists, cardiac anesthesiologists, cardiovascular radiologists, and others) that is actively engaged in the treatment of congenital and/or structural heart disease. The Heart Team should have experience in the treatment of conditions of the pulmonary valve and the RVOT. Each case should be discussed among the Heart Team members (medical-surgical conference) and the best approach for each patient is determined. 
TABLE 1. Characteristic of tPVR Program

Institutional cath volume

Interventionalist

Device training

Surgical program

Data registry

Existing programs

New programs

Outcomes
150 congenital/structural heart disease caths/year

100 diagnostic and therapeutic cases/year including 50 congenital/structural heart intervention cases/year

Experience with stent implantation for branch pulmonary arteries and conduit stenosis

Board certified/eligible or the equivalent in interventional cardiology, pediatric cardiology, or thoracic surgery

Suitable training on devices to be used

The program is or is associated with a congenital/structural open-heart program that performs $>100$ open surgical cases or the program is an adult-congenital cardiac program that performs 25 adult-congenital cardiac operations/year There should be ECMO capabilities in the institution for the rare case when needed

All cases must be submitted to a national clinical database

Programs that have already performed 10 tPVR procedures may be considered established

New programs should have sufficient volume to perform 5 cases per year or 10 over the first 2 years Patients should have $80 \%$ freedom from reintervention at 1 year
Furthermore, the institution should have extracorporeal membrane oxygenation ECMO capabilities for the rare patient who may require such support.

3. Imaging requirements

a. Echocardiographic laboratory: transthoracic and transesophageal echocardiographic capabilities with sonographers and echocardiographers experienced in congenital heart disease.

b. Radiologic imaging: cardiac $\mathrm{CT}$ and cardiac MRI capabilities.

c. Cardiovascular catheterization laboratory or hybrid suite equipped with a fixed X-ray system with fluoroscopy offering high-resolution imaging, recording and archiving capability. A biplane unit is desirable.

d. Hemodynamic evaluation, recording and retrieval capabilities.

e. The institution should be a participant in a national registry (IMPACT) collecting data on all patients undergoing transcatheter pulmonary valve replacement, in a manner similar to sites performing TAVR. The professional societies will determine the exact registry that will collect data on patients undergoing tPVR to follow the outcomes of such patients and, hopefully, to compare these outcomes to patients who undergo the traditional surgical approach.

f. ECMO: availability of ECMO support for the rare case when needed.

\section{Operator Requirements}

The individual operator interested in performing tPVR should meet the following criteria:

1. The operator performs congenital and/or structural heart interventions. In addition to experience with balloon valvuloplasty, experience in stenting of branch pulmonary arteries and RVOT is needed for the treatment of complex lesions. To minimize the risk of coronary artery compression, the operator should have full knowledge and experience assessing the location of the coronary arteries in relation to the RVOT. This assessment is crucial in every patient who undergoes percutaneous pulmonary valve implantation. ${ }^{24}$ The authors encourage collaboration with adult cardiologists when assessing the coronary arteries relation to the RVOT.

2. The operator should perform at least 100 diagnostic/interventional cases per year, 50 of which should be interventional (congenital/structural) cases per year. The rationale for demanding higher number than what we have published in the tAVR document is the fact that tPVR is a much more demanding procedure than tAVR or even percutaneous mitral valve repair. tPVR is a more challenging procedure with more potential serious complications, including stent embolization that requires certain skills in retrieving embolized foreign body, rupture of the branch pulmonary arteries that may lead to catastrophic consequences, and rupture of the RVOT that may lead to tamponade and death. Finally, compression of the coronary arteries induced by stenting the RVOT may occur and may lead to death. Based on this, the writing committee felt that the operator interested in performing tPVR should practice more cases on annual basis.

3. The operator should attend a peer-to-peer training course as recommended by the United States FDA. Such courses should discuss the procedure in detail (selection of patients; baseline assessment; procedural technique; potential complications and their management and how to avoid such complications).

4. The operator should perform a simulated case if available.

5. At a minimum, the first 3 cases should be performed under the supervision of a proctor. Proctorship is essential in tPVR and at the end of the proctoring session the trainee should be cleared by the proctor to proceed with tPVR independently.

\section{References}

1. Tommaso CL, Bolman RM III, Feldman T, et al. Multisociety (AATS, ACCF, SCAI, and STS) expert consensus statement: Operator and institutional 
requirements for transcatheter valve repair and replacement, Part 1: Transcatheter aortic valve replacement. J Am Coll Cardiol. 2012;59:2028-42.

2. Therrien J, Siu SC, McLaughlin PR, et al. Pulmonary valve replacement in adults late after repair of tetralogy of fallot: Are we operating too late? J Am Coll Cardiol. 2000;36:1670-5.

3. Aggarwal S, Garekar S, Forbes TJ, et al. Is stent placement effective for palliation of right ventricle to pulmonary artery conduit stenosis? J Am Coll Cardiol. 2007; 49:480-4.

4. Peng LF, McElhinney DB, Nugent AW, et al. Endovascular stenting of obstructed right ventricle-to-pulmonary artery conduits: A 15-year experience. Circulation. 2006;113:2598-605.

5. Nishimura RA, Otto CM, Bonow RO, Carabello BA, Erwin JP III, Guyton RA, et al. AHA/ACC guideline for the management of patients with valvular heart disease: a report of the American College of Cardiology/American Heart Association Task Force on Practice Guidelines. J Am Coll Cardiol. 2014;63:e57-185.

6. Warnes CA, Williams RG, Bashore TM, et al. ACC/AHA 2008 guidelines for the management of adults with congenital heart disease: Executive summary: A report of the American College of Cardiology/American Heart Association task force on practice guidelines. Circulation. 2008; 118:2395-451.

7. Ong K, Boone R, Gao M, et al. Right ventricle to pulmonary artery conduit reoperations in patients with tetralogy of fallot or pulmonary atresia associated with ventricular septal defect. Am J Cardiol. 2013;111:1638-43.

8. Batlivala SP, Emani S, Mayer JE, McElhinney DB. Pulmonary valve replacement function in adolescents: A comparison of bioprosthetic valves and homograft conduits. Ann Thorac Surg. 2012;93:2007-16.

9. Miskovic A, Monsefi N, Doss M, et al. Comparison between homografts and Freestyle ${ }^{\circledR}$ bioprosthesis for right ventricular outflow tract replacement in Ross procedures. Eur J Cardiothorac Surg. 2012;42:927-33.

10. Poynter JA, Eghtesady P, McCrindle BW, et al. Association of pulmonary conduit type and size with durability in infants and young children. Ann Thorac Surg.. 2013;96:1695-701.

11. Tweddell JS, Pelech AN, Frommelt PC, et al. Factors affecting longevity of homograft valves used in RVOT reconstruction for CHD. Circulation. 2000; 102(Suppl 3):III130-5.

12. Homann M, Haehnel JC, Mendler N, et al. Reconstruction of the RVOT with valved biological conduits: 25 years experience with allografts and xenografts. Eur J Cardiothorac Surg. 2000;17:624-30.
13. Oechslin E, Harrison DA, Harris I, et al. Reoperation in adults with repair of tetralogy of fallot: Indications and outcomes. J Thorac Cardiovasc Surg. 1999;118: 245-51.

14. Bonhoeffer P, Boudjemline Y, Saliba Z, et al. Transcatheter implantation of a bovine valve in pulmonary position. A lamb study. Circulation. 2000;102:813-6.

15. Bonhoeffer P, Boudjemline Y, Saliba Z, et al. Percutaneous replacement of pul monary valve in a right-ventricle to pulmonary-artery prosthetic conduit with valve dysfunction. Lancet. 2000;356:1403-5.

16. Garay F, Webb J, Hijazi ZM. Percutaneous replacement of pulmonary valve using the Edwards-Cribier percutaneous heart valve: First report in a human patient. Catheter Cardiovasc Interv. 2006;67:659-62.

17. Khambadkone S, Coats L, Tahlor A, et al. Percutaneous pulmonary valve implantation in humans results in 59 consecutive patients. Circulation. 2005;112: 1189-97.

18. Lurz P, Coats L, Khambadkone S, et al. Percutaneous pulmonary valve implantation impact of evolving technology and learning curve on clinical outcomes. Circulation. 2008;117:1964-72.

19. Zahn EM, Hellenbrand WE, Lock JE, McElhinney DB. Implantation of the Melody transcatheter pulmonary valve in patients with a dysfunctional right ventricular outflow tract conduit early results from the U.S. Clinical trial. J Am Coll Cardiol. 2009;54:1722-9.

20. McElhinney DB, Hellenbrand WE, Zahn EM. Short- and medium-term outcomes after transcatheter pulmonary valve placement in the expanded multicenter US Melody valve trial. Circulation. 2010;122:507-16.

21. Boone RH, Webb JG, Horlick E, Benson L, Cao QL, et al. Transcatheter pulmonary valve implantation using the Edwards SAPIEN transcatheter heart valve. Cathet Cardiovasc Interven. 2010;75:286-94.

22. Kenny D, Hijazi ZM, Kar S, et al. Percutaneous implantation of the Edwards SA PIEN transcatheter heart valve for conduit failure in the pulmonary position. JAm Coll Cardiol. 2011;58:2248-56.

23. Kenny D, Hijazi ZM. Transcatheter pulmonary valve replacement: Current status and future potentials. Interv Cardiol Clin. 2013;2:181-93.

24. Morray BH, McElhinney DB, Cheatham JP, et al. Risk of coronary artery compression among patients referred for transcatheter pulmonary valve implantation: A multicenter experience. Circ Cardiovasc Interven. 2013;6:535-42.

25. McElhinney DB, Benson LN, Eicken A, Kreutzer J, Padera RF, Zahn EM. Infective endocarditis after transcatheter pulmonary valve replacement using the Melody valve: Combined results of 3 prospective North American and European studies. Circ Cardiovasc Interv. 2013;6:292-300. 
APPENDIX TABLE 1. Author relationships with industry (RWI) and other entities (relevant)-SCAI/AATS/ACC/STS operator and institutional requirements for transcatheter valve repair and replacement, part III-pulmonic valve

\begin{tabular}{|c|c|c|c|c|c|c|}
\hline Committee member & Consultant & $\begin{array}{c}\text { Speaker's } \\
\text { bureau }\end{array}$ & $\begin{array}{l}\text { Ownership/ } \\
\text { partnership/ } \\
\text { principal }\end{array}$ & Personal research & $\begin{array}{l}\text { Institutional, } \\
\text { organizational } \\
\text { or other } \\
\text { financial benefit }\end{array}$ & $\begin{array}{l}\text { Expert } \\
\text { witness }\end{array}$ \\
\hline Ziyad M. Hijazi, MD & Venus Medtech & None & Colibri Heart Valve* & None & PICS Foundation* & None \\
\hline Carlos E. Ruiz, MD & None & None & None & None & None & None \\
\hline Evan Zahn, MD & Medtronic* & None & None & None & None & None \\
\hline Gabriel S. Aldea, MD & None & None & None & None & None & None \\
\hline Emile A. Bacha, MD & None & None & None & None & None & None \\
\hline Joseph Bavaria, MD & St. Jude Medical & None & None & $\begin{array}{l}\text { Edwards Lifesciences, }{ }^{*} \\
\text { Medtronic** }\end{array}$ & None & None \\
\hline R. Morton Bolman III, MD & None & None & None & None & None & None \\
\hline Duke E. Cameron, MD & None & None & None & None & None & None \\
\hline Larry S. Dean, MD & None & None & None & Edwards Lifesciences $\dagger$ & None & None \\
\hline Ted Feldman, MD & $\begin{array}{l}\text { WL Gore, Edwards } \\
\text { Lifesciences, Boston } \\
\text { Scientific, Abbott }\end{array}$ & None & None & $\begin{array}{l}\text { WL Gore, }{ }^{*} \text { Edwards } \\
\text { Lifesciences, }{ }^{*} \text { Abbott,* } \\
\text { Boston Scientific* }\end{array}$ & None & None \\
\hline David Fullerton, MD & None & None & None & None & None & None \\
\hline Eric Horlick, MDCM & $\begin{array}{l}\text { St. Jude Medical, } \dagger \\
\text { Medtronic, WL Gore, } \\
\text { Edwards Lifesciences }\end{array}$ & None & None & None & None & None \\
\hline Michael J. Mack, MD & None & None & None & Edwards Lifesciences* & None & None \\
\hline D. Craig Miller, MD & Abbott, Medtronic & None & None & Edwards Lifesciences* & None & None \\
\hline Marc R. Moon, MD & None & None & None & None & None & None \\
\hline Alfredo Trento, MD & None & None & None & None & None & None \\
\hline Carl L. Tommaso, MD & None & None & None & None & None & None \\
\hline Debabrata Mukherjee, MD & None & None & None & None & None & None \\
\hline Richard Ringel, MD & None & None & None & Medtronic-NuMed* & None & None \\
\hline
\end{tabular}

This table represents all healthcare relationships of committee members with industry and other entities that were reported by authors determined to be relevant to this document at the time this document was under development. The table does not necessarily reflect RWI at the time of publication. A person is deemed to have a significant interest in a business if the interest represents ownership of $\geq 5 \%$ of the voting stock or share of the business entity, or ownership of $\geq \$ 10,000$ of the fair market value of the business entity; or if funds received by the person from the business entity exceed $5 \%$ of the person's gross income for the previous year. Relationships that exist with no financial benefit are also included for the purpose of transparency. Relationships in this table are modest unless otherwise noted. Please refer to http://www.acc.org/guidelines/about-guidelines-and-clinicaldocuments/relationships-with-industry-policy for definitions of disclosure categories or additional information about the American College of Cardiology (ACC) Disclosure Policy for Writing Committees. *No financial benefit. †Significant relationship. 
APPENDIX TABLE 2. Author relationships with industry (RWI) and other entities (comprehensive)-SCAI/AATS/ACC/STS operator and institutional requirements for transcatheter valve repair and replacement, part III: Pulmonic valve

\begin{tabular}{|c|c|c|c|c|c|c|}
\hline Committee member & Consultant & $\begin{array}{c}\text { Speaker's } \\
\text { bureau }\end{array}$ & $\begin{array}{c}\text { Ownership/ } \\
\text { partnership/ } \\
\text { principal }\end{array}$ & Personal research & $\begin{array}{c}\text { Institutional, } \\
\text { organizational } \\
\text { or other } \\
\text { financial benefit }\end{array}$ & $\begin{array}{l}\text { Expert } \\
\text { witness }\end{array}$ \\
\hline Ziyad M. Hijazi, MD & $\begin{array}{l}\text { Occlutech, } \dagger \\
\quad \text { NuMED Inc. } \dagger\end{array}$ & None & Colibri Heart Valve* & None & $\begin{array}{l}\text { PICS } \\
\text { Foundation* }\end{array}$ & None \\
\hline Carlos E. Ruiz, MD & None & None & None & None & None & None \\
\hline Evan Zahn, MD & Medtronic* & None & None & None & None & None \\
\hline Gabriel S. Aldea, MD & None & None & None & None & None & None \\
\hline Emile A. Bacha, MD & Cormatrix & None & None & None & None & None \\
\hline Joseph Bavaria, MD & St. Jude Medical & None & None & $\begin{array}{l}\text { Sorin,* } \\
\text { Edwards Lifesciences,* } \\
\text { Medtronic* }\end{array}$ & None & 2013 \\
\hline R. Morton Bolman III, MD & None & None & None & Glaxo-Smith-Kline* & None & None \\
\hline Duke E. Cameron, MD & None & None & None & None & None & None \\
\hline Larry S. Dean, MD & Phillips Medical & $\begin{array}{l}\text { Daiichi } \\
\quad \text { Sankyo, } \\
\text { Lilly }\end{array}$ & $\begin{array}{c}\text { Emageon (stock } \\
\text { ownership) }\end{array}$ & Edwards Lifesciences $\dagger$ & None & None \\
\hline Ted Feldman, MD & $\begin{array}{l}\text { WL Gore, Edwards } \\
\text { Lifesciences, Abbott, } \\
\text { Boston Scientific }\end{array}$ & None & None & $\begin{array}{l}\text { WL Gore,* Edwards } \\
\text { Lifesciences,* Abbott,* } \\
\text { Boston Scientific Corporation* }\end{array}$ & None & None \\
\hline David Fullerton, MD & None & None & None & None & None & None \\
\hline Eric Horlick, MDCM & $\begin{array}{l}\text { St. Jude Medical, } \dagger \\
\text { Medtronic, Gore, } \\
\text { Edwards Lifesciences }\end{array}$ & None & None & $\begin{array}{l}\text { Gore,* St. Jude Medical, } \\
\text { Medtronic* }\end{array}$ & None & 2004,2012 \\
\hline Michael J. Mack, MD & None & None & None & Edwards Lifesciences* & None & None \\
\hline D. Craig Miller, MD & $\begin{array}{l}\text { GenTAC/HHLBI under } \\
\text { contract to RTI, Abbott } \\
\text { Vascular MitraClip, } \\
\text { Medtronic, Partner U.S. }\end{array}$ & None & None & Edwards Lifesciences* & None & None \\
\hline Marc R. Moon, MD & None & None & None & Carbomedics* & None & 2012 \\
\hline Alfredo Trento, MD & None & None & None & None & None & None \\
\hline Carl L. Tommaso, MD & Treasurer, SCAI* & None & None & None & None & 2004,2006 \\
\hline Debabrata Mukherjee, MD & None & None & None & None & None & None \\
\hline Richard Ringel, MD & None & None & None & Medtronic-NuMed* & None & $\begin{array}{l}2010,2010, \\
2010,2011 \\
2011,2011\end{array}$ \\
\hline
\end{tabular}

This table represents all healthcare relationships of committee members with industry and other entities that were reported by authors, including those not deemed to be relevant to this document, at the time this document was under development. The table does not necessarily reflect RWI at the time of publication. A person is deemed to have a significant interest in a business if the interest represents ownership of $\geq 5 \%$ of the voting stock or share of the business entity, or ownership of $\geq \$ 10,000$ of the fair market value of the business entity; or if funds received by the person from the business entity exceed $5 \%$ of the person's gross income for the previous year. Relationships that exist with no financial benefit are also included for the purpose of transparency. Relationships in this table are modest unless otherwise noted. Please refer to http://www.cardiosource.org/Science-AndQuality/Practice-Guidelines-and-Quality-Standards/Relationships-With-Industry-Policy.aspx for definitions of disclosure categories or additional information about the ACC Disclosure Policy for Writing Committees. According to the ACC, a person has a relevant relationship IF: a) The relationship or interest relates to the same or similar subject matter, intellectual property or asset, topic, or issue addressed in the document; or b) The company/entity (with whom the relationship exists) makes a drug, drug class, or device addressed in the document, or makes a competing drug or device addressed in the document; or c) The person or a member of the person's household has a reasonable potential for financial, professional, or other personal gain or loss as a result of the issues/content addressed in the document. *No financial benefit. †Significant relationship. 
APPENDIX TABLE 3. Reviewer relationships with industry (RWI) and other entities (relevant)-SCAI/AATS/ACC/STS operator \& institutional requirements for transcatheter valve repair and replacement, part III: Pulmonic valve

\begin{tabular}{|c|c|c|c|c|c|c|c|}
\hline Peer reviewer & Representation & Consultant & $\begin{array}{c}\text { Speaker's } \\
\text { bureau }\end{array}$ & $\begin{array}{c}\text { Ownership/ } \\
\text { partnership/ } \\
\text { principal }\end{array}$ & $\begin{array}{l}\text { Personal } \\
\text { research }\end{array}$ & $\begin{array}{c}\text { Institutional, } \\
\text { organizational, } \\
\text { or other } \\
\text { financial benefit }\end{array}$ & $\begin{array}{l}\text { Expert } \\
\text { witness }\end{array}$ \\
\hline Carole A. Warnes, MD & ACC & None & None & None & None & None & None \\
\hline Geetha Raghuveer, MBBS & ACC & None & None & None & None & None & None \\
\hline Hani Jneid, MD & ACC & None & None & None & None & None & None \\
\hline Andrew Wang, MD & ACC & None & None & None & $\begin{array}{l}\text { Gilead Sciences, }{ }^{*} \\
\text { Edwards } \\
\text { Lifesciences,* } \\
\text { Abbott Vascular* }\end{array}$ & None & None \\
\hline Robert H. Beekman III, MD & $\mathrm{ACC}$ & St. Jude Medical & None & None & None & None & None \\
\hline Emile Bacha, MD & ACC & Cormatrix & None & None & None & None & None \\
\hline Joaquin E. Cigarroa, MD & $\mathrm{ACC}$ & None & None & None & None & None & None \\
\hline Robert N. Piana, MD & ACC & $\begin{array}{l}\text { WL Gore, HCRI, } \\
\text { Axio Research }\end{array}$ & None & None & $\begin{array}{l}\text { Amplatzer } \\
\text { Corporation }\end{array}$ & Vascutek & None \\
\hline David R. Holmes, Jr, MD & $\mathrm{ACC}$ & None & None & None & None & None & None \\
\hline John H. Calhoon, MD & STS & None & None & None & None & None & None \\
\hline Hersh S. Maniar, MD & STS & None & None & None & None & None & None \\
\hline Carl Backer, MD & AATS & None & None & None & None & None & None \\
\hline Joseph Dearani, MD & AATS & None & None & None & None & None & None \\
\hline Daniel S. Levi, MD & SCAI & None & None & None & None & None & None \\
\hline Phillip Moore, MD & SCAI & None & None & None & None & None & None \\
\hline
\end{tabular}

This table represents the relationships of reviewers with industry and other entities that were disclosed at the time of peer review and determined to be relevant to this document. It does not necessarily reflect RWI at the time of publication. A person is deemed to have a significant interest in a business if the interest represents ownership of $\geq 5 \%$ of the voting stock or share of the business entity, or ownership of $\geq \$ 10,000$ of the fair market value of the business entity; or if funds received by the person from the business entity exceed $5 \%$ of the person's gross income for the previous year. A relationship is considered to be modest if it is less than significant under the preceding definition. Relationships that exist with no financial benefit are also included for the purpose of transparency. Relationships in this table are modest unless otherwise noted. Names are listed in alphabetical order within each category of review. Please refer to http://www.acc.org/guidelines/about-guidelines-and-clinical-documents/relationships-with-industry-policy for definitions of disclosure categories or additional information about the ACC Disclosure Policy for Writing Committees. According to the ACC, a person has a relevant relationship IF: a) The relationship or interest relates to the same or similar subject matter, intellectual property or asset, topic, or issue addressed in the document; or b) The company/entity (with whom the relationship exists) makes a drug, drug class, or device addressed in the document, or makes a competing drug or device addressed in the document; or c) The person or a member of the person's household has a reasonable potential for financial, professional, or other personal gain or loss as a result of the issues/content addressed in the document. $*$ Significant relationship. 